\title{
Pengembangan Modul Sistem Sirkulasi Berdasarkan Penelitian Hematologi Tikus DMT2
}

\author{
Badriyatur Rahma Fidiya ${ }^{1}$, Abdul Gofur ${ }^{1}$, Sri Rahayu Lestari ${ }^{2}$ \\ ${ }^{1}$ Pendidikan Biologi-Universitas Negeri Malang \\ ${ }^{2}$ Biologi-Universitas Negeri Malang
}

\begin{tabular}{l}
\hline \hline INFO ARTIKEL \\
\hline Riwayat Artikel: \\
Diterima: 07-05-2019 \\
Disetujui: 16-10-2019 \\
\hline
\end{tabular}

\section{Kata kunci:}

module development; circulation system; hematology; pengembangan modul; sistem sirkulasi; hematologi

\begin{abstract}
This study aims to develop a circulation system module based on hematological studies of T2DM rats. The module is developed based on the adaptation of the ADDIE developmental model. A module that has been developed then went through validation which is material aspect and teaching materials aspect. Practical tests were carried out by an expert in education practitioners and 10 students who had taken Animal Physiology and Humanities courses at the State University of Malang. The average results obtained from the validation of material experts is $95.8 \%$ and teaching material experts $91.4 \%$. While the results of field practitioner expert trials amounted to 97, 9\% and based on student responses an average of $90.3 \%$ are obtained. Based on these results the module can be said to be very valid and very practical to use in the teaching and learning process.
\end{abstract}

ABSTRAK

\begin{abstract}
Abstrak: Penelitian ini bertujuan untuk mengembangkan modul sistem sirkulasi berdasarkan penelitian hematologi tikus DMT2. Modul dikembangkan berdasarkan adaptasi model pengembangan ADDIE. Modul yang telah dikembangkan kemudian melalui tahap validasi materi dan bahan ajar. Uji kepraktisan dilakukan oleh ahli praktisi pendidikan dan 10 mahasiswa yang telah menempuh matakuliah Fisiologi Hewan dan Manusia Universitas Negeri Malang. Rata-rata yang diperoleh dari hasil validasi ahli materi $95,8 \%$, ahli bahan ajar $91,4 \%$, uji coba ahli praktisi lapangan $97,9 \%$ dan respon mahasiswa rata-rata 90, 3\%. Berdasarkan hasil tersebut, modul dapat dikatakan sangat valid dan praktis untuk digunakan dalam proses belajar mengajar.
\end{abstract}

\author{
Alamat Korespondensi: \\ Badriyatur Rahma Fidiya \\ Pendidikan Biologi \\ Universitas Negeri Malang \\ Jalan Semarang 5 Malang \\ E-mail: b.rahma.f@gmail.com
}

Pendidikan perguruan tinggi mencakup program diploma, sarjana, magister, doktor, profesi, dan program spesialis yang diselenggarakan oleh perguruan tinggi berdasarkan kebudayaan bangsa Indonesia (Permendikbud No 49, 2014). Pendidikan perguruan tinggi merupakan salah satu jenjang pendidikan yang penting bagi perkembangan Sumber Daya Manusia karena perkembangan Sumber Daya Manusia dan pendidikan merupakan dua hal yang saling terkait dan tidak dapat dipisahkan (Bastian, 2006). Pendidikan perguruan tinggi harus memenuhi berbagai kualifikasi yang telah ditetapkan baik oleh Negara atau satuan instansi perguruan tinggi. Kriteria dan jenjang kualifikasi perguruan tinggi mengenai standar kelulusan dan capaian pembelajaran diatur dalam Kerangka Kualifikasi Nasional Indonesia (KKNI). KKNI menyatakan bahwa perguruan tinggi jenjang kualifikasi dan capaian pembelajaran untuk S1 masuk pada level 6. Pada level ini peserta didik dituntut untuk mampu mengaplikasikan bidang keahliannya dan memanfaatkan ilmu pengetahuan serta teknologi, dan seni pada bidangnya untuk penyelesaian masalah, serta beradaptasi terhadap situasi yang dihadapi (Perpres No 8, 2012).

Perguruan tinggi yang menerapkan kriteria kualifikasi KKNI dan SN DIKTI dalam pencapaian kelulusan salah satunya adalah Jurusan Biologi dalam lingkup Fakultas Matematika dan Ilmu Pengetahuan Alam Universitas Negeri Malang. Peserta didik diwajibkan menyesuaikan program kuliah sesuai dengan Satuan Kredit Semester yang ditentukan sesuai program studi dan keahlian yang diminati untuk mencapai lulusan yang sesuai dengan KKNI dan SN DIKTI (Permendikbud No 49, 2014). Salah satu matakuliah yang wajib ditempuh dan diambil dalam Jurusan Biologi UM adalah matakuliah Fisiologi Hewan dan Manusia. Fisiologi hewan dan manusia mempelajari mengenai struktur dan proses fisiologis yang terjadi pada tubuh hewan dan manusia.

Fisiologi Hewan dan Manusia termasuk dalam matakuliah yang cukup sulit untuk dipelajari (Michael, 2007;Colthorpe, Abe, \& Ainscough, 2018). Hal ini sesuai dengan hasil analisis yang dilakukan pada mahasiswa, dimana mahasiswa masih merasa kesulitan dalam memahami materi karena materi sangat luas dan bersifat abstrak. Hasil analisis kebutuhan dari 41 mahasiswa, sebanyak $76.9 \%$ mahasiswa masih merasa kesulitan dalam materi Fisiologi Hewan dan Manusia. Faktor lain yang 
mengakibatkan mahasiswa kesulitan adalah dari segi bahan ajar yang digunakan. Bahan ajar yang digunakan kebanyakan merupakan bahan ajar berbahasa asing. Sebanyak 63\% mahasiswa menyatakan kesulitan dalam memahami isi materi karena penggunaan bahasa asing dan bahan ajar yang digunakan kurang menarik. Hasil analisis kebutuhan juga menunjukkan bahwa belum adanya bahan ajar yang terintegrasi kehidupan sehari-hari (kontekstual) sehingga mahasiswa kurang dapat mengaitkan materi dengan kehidupan sehari-hari.

Berdasarkan paparan mengenai tuntutan pembelajaran, hasil observasi, dan kebutuhan dosen serta mahasiswa, perlu adanya solusi nyata yang dapat mendukung kegiatan belajar mengajar. Solusi yang dapat ditawarkan adalah dengan pengembangan bahan ajar yang kontekstual dan memuat berbagai cara untuk menjawab tuntutan yang ada. Bahan ajar yang memiliki berbagai kelebihan untuk mendukung proses pembelajaran yaitu modul. Modul merupakan bahan ajar yang mudah diaplikasikan dalam kehidupan sehari-hari dan dapat memberdayakan keterampilan memecahkan masalah serta keterampilan lain seperti halnya kemampuan berpikir kritis (Alquriyah \& Prayitno, 2014; Suarsana \& Mahayukti, 2013). Modul dapat meningkatkan kemandirian, hasil belajar dan mengandung serangkaian pengalaman belajar yang sistematis sehingga dapat membantu mahasiswa mencapai kompetensi lulusan, tujuan pembelajaran, dan prestasi (Hartoyo, 2009; Hapsari, Suyanto, Budiwati, 2016). Modul yang mengandung materi dan permasalahan kontekstual dapat secara efektif meningkatkan pemahaman peserta didik (Sudarno, Sunanrno, \& Sarwanto, 2015).

Penggunaan masalah kontekstual dalam pembelajaran dapat mempermudah peserta didik dalam memahami suatu materi karena berangkat dari suatu permasalahan kontekstual, masalah nyata dalam kehidupan sehingga dapat mengasah kemampuan pemecahan masalah dan berpikir tingkat tinggi (Fitzpatrick, 2008; Drăghicescu, Petrescu, Cristea, Gorghiu, \& Gorghiu, 2014; Bergman et al., 2015). Permasalahan kontekstual merupakan suatu masalah yang ada di sekitar mahasiswa. Salah satu masalah yang dapat diintegrasikan adalah permasalahan diabetes. Diabetes merupakan salah satu penyakit yang umum diderita di Indonesia berdasarkan hasil penelitian epidemologis pada tahun 2000-an yang menyatakan jumlah penderita diabetes di Indonesia mencapai 8,4 juta orang. Jumlah tersebut menempatkan Indonesia pada peringkat keempat Negara dengan jumlah penderita diabetes mellitus tertinggi setelah India, China, dan Amerika Serikat. Berdasarkan hasil analisis pada mahasiswa juga menyatakan bahwa banyak penderita diabetes dilingkungan mahasiswa. Jumlah ini dipekirakan akan terus meningkat lebih dari dua kali lipat pada tahun 2030 bila tidak diimbangi dengan penanganan yang tepat (Mahendra, Krisnatuti, Tobing, \& Alting, 2008). Dalam memahami permasalahan dapat dilakukan uji hematologi sederhana yang berkaitan erat dengan sistem sirkulasi untuk mengenalkan peserta didika pada masalah nyata pada sekeliling sehingga materi tidak abstrak dan mudah dipahami. Tujuan penelitian ini adalah untuk menghasilkan bahan ajar berupa modul sistem sirkulasi matakuliah Fisiologi Hewan dan Manusia pada S1 Pendidikan Biologi Universitas Negeri Malang berdasarkan hematologi tikus DMT2.

\section{METODE}

Penelitian ini merupakan jenis penelitian Reserch and Development (Penelitian dan pengembangan). Penelitian ini bertujuan untuk mengembangkan suatu bahan ajar berupa modul. Modul yang dikembangkan diadaptasi berdasarkan tahapan pengembangan ADDIE oleh Branch (2009), namun tidak semua tahap dilaksanakan. Langkah pengembangan yang dilakukan, meliputi (1) analyze (analisis), (2) design (desain), (3) develop (pengembangan), dan (4) evaluate (evaluasi). Perancangan isi modul dikembangkan berdasarkan atas penelitian hematologi pada tikus model DMT2. Pada tahap pengembangan dilakukan uji coba untuk mengetahui kevalidan dan kepraktisan dari modul yang dikembangkan.

Validasi ahli materi dilakukan oleh ahli materi yang merupakan dosen yang berpengalaman dalam bidang biologi khususnya Fisiologi Hewan dan Manusia. Ahli bahan ajar adalah orang yang memiliki pengalaman dalam pengembangan bahan ajar. Tujuan dilakukan uji coba oleh ahli bahan ajar adalah untuk mengetahui seberapa interaktifkah bahan ajar yang dikembangkan. Selain validasi, dilakukan pula uji praktisi lapangan dan uji coba kelompok kecil. Uji coba pada praktisi lapangan dilakukan untuk mengetahui tingkat kesesuaian materi yang disajikan dalam modul dan untuk mengetahui apakah materi ini sesuai digunakan oleh mahasiswa serta sesuai dengan capaian pembelajaran yang ingin dicapai. Uji coba kelompok kecil dilakukan kepada mahasiswa setelah tahap validasi masing-masing ahli dilaksanakan dan telah melalui tahap perbaikan. Tujuan uji coba kelompok kecil adalah untuk mendapatkan data yang digunakan dalam menentukan kepraktisan bahan ajar dan mendapatkan review modul yang nantinya digunakan sebagai pertimbangan dalam memperbaiki modul. Uji coba kelompok kecil dilakukan pada 14 orang mahasiswa yang telah menempuh matakuliah Fisiologi Hewan dan Manusia.

Data validasi ahli materi, bahan ajar, praktisi lapangan, dan respons mahasiswa didapatkan dari angket yang berisi pertanyaan mengenai materi, bahan ajar, maupun kesesuaian modul dengan pembelajaran, dan kemenarikan modul. Data yang didapatkan adalah data kualitatif berupa saran dan masukan, serta data kuantitatif yang didaptkan dari penskoran. Teknik penskoran yang dilakukan menggunakan skala Likert 1 - 4. Teknik analisis data menggunakan perhitungan nilai rata-rata:

$$
P=\frac{\Sigma x(\text { jumlah jawaban responden })}{\Sigma x i(\text { Jumlah jawaban maksimal })} \times 100 \%
$$

Penskoran dengan skala Likert kemudian dikonversikan ke dalam kriteria tertentu. Kriteria yang digunakan untuk menentukan validitas dari bahan ajar petunjuk praktikum terdapat pada tabel 1, sedangkan kriteria untuk nilai kepraktisan petunjuk praktikum dapat dilihat pada tabel 2. 
Tabel 1. Kriteria Hasil Validitas

\begin{tabular}{ll}
\hline Persentase (\%) & \multicolumn{1}{c}{ Tingkat Validitas } \\
\hline $85,01-100,00$ & Sangat valid, atau dapat digunakan tanpa revisi \\
\hline $70,01-85,00$ & Cukup valid, atau dapat digunakan namun perlu direvisi kecil \\
\hline $50,01-70,00$ & Kurang valid, disarankan tidak dipergunakan karena perlu revisi \\
\hline $01,00-50,00$ & Tidak valid, atau tidak boleh dipergunakan \\
\hline
\end{tabular}

(Sumber: Akbar, 2013)

Tabel 2. Kriteria Hasil Kepraktisan

\begin{tabular}{ll}
\hline Persentase (\%) & \multicolumn{1}{c}{ Tingkat Kepraktisan } \\
\hline $85,01-100,00$ & Sangat praktis, atau dapat digunakan tanpa revisi \\
\hline $70,01-85,00$ & Cukup praktis, atau dapat digunakan namun perlu direvisi kecil \\
\hline $50,01-70,00$ & Kurang praktis, disarankan tidak dipergunakan karena perlu revisi \\
\hline $01,00-50,00$ & Tidak praktis, atau tidak boleh dipergunakan \\
\hline
\end{tabular}

(Sumber: Diadaptasi dari Akbar, 2013)

HASIL

Produk yang dikembangkan pada penelitian ini merupakan bahan ajar berupa modul sistem sirkulasi untuk matakuliah Fisiologi Hewan dan Manusia. Modul ini dikembangkan berdasarkan hasil penelitian hematologi tikus DMT2. Modul yang dikembangkan berisi tiga kegiatan yang disusun mengikuti capaian pembelajaran dan disesuaikan dengan tuntutan KKNI. Tingkat kevalidan produk didapatkan dari hasil validasi oleh ahli materi dan bahan ajar. Hasil kevalidan materi dalam produk ini termasuk dalam kriteria sangat valid yaitu 95, 8\% (Tabel 3). Kevalidan bahan ajar termasuk dalam kriteria sangat valid yaitu 91, 4\% (Tabel 4). Hasil uji coba ahli praktisi lapangan termasuk dalam kriteria sangat praktis, sebesar 97, 9\% (Tabel 5) dan berdasarkan respons mahasiswa rata-rata sebesar 90,3\% (Tabel 6). Berdasarkan hasil tersebut modul dapat dikatakan sangat valid dan sangat praktis untuk digunakan dalam proses belajar mengajar.

Tabel 3. Data Hasil Validasi Modul oleh Ahli Materi

\begin{tabular}{clll}
\hline No & Indikator & Rata-rata \% & Kriteria \\
\hline 1. & Kesesuaian dengan CPMK & $91,7 \%$ & Sangat Valid \\
2. & Keakuratan Materi & $96,4 \%$ & Sangat Valid \\
3. & Kemutakhiran \& Kontekstual & $95 \%$ & Sangat Valid \\
4. & Kelayakan Isi & $100 \%$ & Sangat Valid \\
\hline Rata-rata \% total & $\mathbf{9 5 , 8 \%}$ & Sangat Valid \\
\hline
\end{tabular}

Tabel 4. Data Hasil Validasi Modul oleh Ahli Bahan Ajar

\begin{tabular}{clll}
\hline No & Indikator & Rata-rata \% & Kriteria \\
\hline 1. & Komponen Kegrafisan & $85 \%$ & Cukup Valid \\
2. & Komponen Penyajian & $97,5 \%$ & Sangat Valid \\
3. & Komponen Kebahasaan & $91,8 \%$ & Sangat Valid \\
\hline Rata-rata \% total & $\mathbf{9 1 , 4 \%}$ & Sangat Valid \\
\hline
\end{tabular}

Tabel 5. Data Hasil Uji Kepraktisan Modul oleh Ahli Praktisi Lapangan

\begin{tabular}{clll}
\hline No & Indikator & Rata-rata \% & Kriteria \\
\hline 1. & Komponen Modul & $100 \%$ & Sangat Praktis \\
2. & Komponen kurikulum & $100 \%$ & Sangat Praktis \\
3. & Kelayakan isi & $100 \%$ & Sangat Praktis \\
4. & Tata bahasa & $87,5 \%$ & Sangat Praktis \\
5. & Tampilan & $100 \%$ & Sangat Praktis \\
6. & Mendukung materi & $100 \%$ & Cukup Praktis \\
\hline Rata-rata \% total & $\mathbf{9 7 , 9 \%}$ & Sangat Praktis \\
\hline
\end{tabular}


Tabel 6. Data Hasil Uji Kepraktisan oleh Mahasiswa

\begin{tabular}{ccc}
\hline Mahasiswa & Persentase & Kriteria \\
\hline 1 & $91,7 \%$ & Sangat Praktis \\
2 & $87,5 \%$ & Sangat Praktis \\
3 & $87,5 \%$ & Sangat Praktis \\
4 & $91,7 \%$ & Sangat Praktis \\
5 & $87,5 \%$ & Sangat Praktis \\
6 & $89,6 \%$ & Sangat Praktis \\
7 & $89,6 \%$ & Sangat Praktis \\
8 & $93,7 \%$ & Sangat Praktis \\
9 & $95,6 \%$ & Sangat Praktis \\
10 & $91,7 \%$ & Sangat Praktis \\
\hline Rata-rata \% & $\mathbf{9 0 , 3 \%}$ & Sangat Praktis \\
\hline
\end{tabular}

\section{PEMBAHASAN}

Proses belajar mengajar tidak lepas dari kebutuhan akan bahan ajar (Sungkono, 2007). Salah satu bahan ajar yang dapat digunakan adalah modul. Modul merupakan salah satu bentuk bahan ajar yang dikemas secara utuh, sistematis dan dirancang agar dapat dipelajari secara mandiri oleh peserta didik (Depdiknas, 2008; Prastowo, 2012; Yokhebed, 2018). Modul memuat seperangkat pengalaman belajar yang terencana dan didesain untuk membantu peserta didik menguasai tujuan belajar yang ditetapkan (Syamsul \& Kusrianto, 2008; Rahdiyanta, 2012). Modul dirancang untuk dapat dipelajari secara mandiri oleh peserta didik, memuat materi, topik diskusi, instruksi penggunaan modul, dan tugas yang berorientasi pada peserta didik agar dapat melakukan kegiatan belajar tanpa harus didampingi oleh pendidik secara intensif (Direktorat Tenaga Kependidikan, 2008; Davis, 2015).

Penggunaan modul dalam pembelajaran dapat menjadi alternatif efektif untuk organisasi topik tunggal dan organisasi berbagai topik dalam satu minggu pembelajaran (Bowman, 2014). Modul bersifat self-learning, memuat informasi yang disesuaikan pada tujuan tertentu dan penjelasan agar dapat digunakan belajar secara mandiri, memuat self-checks yang dapat digunakan peserta didik untuk mengetahui kemampuan dalam memahami materi dalam modul sehingga peserta didik dapat mengukur kemampuannya dalam memahami materi. Modul dapat digunakan secara mandiri dimanapun dan kapanpun (Auditor \& Naval, 2014; Billings \& Halstead, 2016).

Modul hasil pengembangan terdiri atas cover atau halaman sampul (sampul luar dan sampul dalam), kata pengantar, daftar isi, profil modul, petunjuk penggunaan modul, capaian pembelajaran, tiga kegiatan pembelajaran, dan daftar rujukan. Modul mengandung soal atau pertanyaan yang disusun untuk mengasah kemampuan pemecahan masalah mahasiswa. Modul memiliki kunci assessment dan jawaban yang dapat digunakan untuk melakukan pengecekan individu agar mahasiswa dapat mengetahui kemampuannya dalam materi yang disajikan. Modul yang disusun harus memuat materi yang kontekstual agar dapat dengan mudah dipahami peserta didik. Modul yang dikembangkan didasarkan pada masalah yang kontekstual yaitu diabetes mellitus dan untuk memenuhi tuntutan KKNI, modul disusun untuk mengasah keterampilan tingkat tinggi dengan didasarkan penelitian hematologi tikus DMT2.

Kegiatan belajar modul terdiri atas tiga hal, yaitu kegiatan I (Sistem sirkulasi hewan dan manusia), kegiatan II (Komponen darah, dan Kegiatan III (Hematologi). Kegiatan I membahas mengenai pengertian sistem sirkulasi dan berbagai sistem sirkulasi pada hewan dan manusia serta fungsinya. Kegiatan II membahas menganai berbagai komponen penyusun darah, Kegiatan III membahas mengenai hematologi yang merupakan salah satu ilmu yang mempelajari darah dan juga terdapat pengaplikasian uji hematologi yang dapat dilakukan mahasiswa agar lebih memahami materi yang disajikan. Pada setiap kegiatan dilengkapi dengan permasalahan yang perlu dipecahkan mahasiswa untuk melatih keterampilan tingkat tinggi.

Hasil penelitian yang telah menghasilkan bahan ajar berupa modul kemudian dilakukan validasi untuk mengetahui validitas bahan ajar tersebut. Bahan ajar dikatakan sangat valid atau dapat digunakan dengan revisi apabila memperoleh tingkat pencapaian 81-100 (Akbar, 2013). Hasil kevalidan materi dalam produk ini termasuk dalam kriteria sangat valid yaitu 95,8\%, hal ini berarti materi yang disajikan dalam modul memenuhi konsep dan tidak melenceng. Kevalidan bahan ajar termasuk dalam kriteria sangat valid yaitu 91, 4\%, hal ini berarti modul yang dikembangkan telah sesuai dengan aturan bahan ajar yang ada. Hasil uji coba ahli praktisi lapangan termasuk dalam kriteria sangat praktis, sebesar 97,9\% dan berdasarkan respons mahasiswa rata-rata sebesar 90,3\%, hal ini berarti modul yang dikembangkan praktis digunakan dalam pembelajaran dan sesuai dengan tuntutan pembelajaran di Universitas Negeri Malang. Berdasarkan hasil tersebut modul dapat dikatakan sangat valid dan sangat praktis untuk digunakan dalam proses belajar mengajar.

Kelebihan modul sistem sirkulasi dibandingkan dengan bahan ajar yang lain, yaitu (1) modul ini dilengkapi dengan petunjuk penggunaan modul, permasalahan, rangkuman, soal latihan, kunci jawaban, dan penilaian yang memudahkan mahasiswa untuk mengukur pemahamannya terhadap materi, (2) modul berbentuk cetak sehingga mempermudah mahasiswa untuk mempelajarinya, (3) modul dilengkapi dengan gambar dan ilustrasi berwarna sehingga dapat menarik minat mahasiswa untuk mempelajarinya, (4) permasalahan yang disajikan dalam modul disusun berdasarkan indikator pemecahan masalah sehingga dapat digunakan untuk melatih keterampilan tingkat tinggi mahasiswa, dan (5) materi dalam modul disusun 
berdasarkan permasalahan kontekstual dan hasil penelitian yang dapat digunakan sebagai informasi tambahan dalam mempelajari modul dan contoh penerapan pemecahan masalah.

\section{SIMPULAN}

Produk hasil pengembangan ini berupa modul sistem sirkulasi yang telah dirancang sesuai dengan model pengembangan ADDIE. Modul yang dikembangkan berdasarkan hasil penelitian hematologi tikus DMT2 tergolong valid dan layak untuk digunakan dalam proses belajar mengajar. Modul yang dikembangkan juga menarik minat mahasiswa untuk mempelajarinya karena berwarna dan menggunakan bahasa Indonesia yang komunikatif dan mudah dipahami. Berdasarkan kesimpulan hasil pengembangan modul, modul sistem sirkulasi dapat menunjang pembelajaran. Modul ini disarankan untuk diuji coba lebih luas, diseminarkan, dibuat artikel maupun dilatihhkan.

\section{DAFTAR RUJUKAN}

Akbar, S. (2013). Instrumen Perangkat Pembelajaran. Bandung. Bandung: Remaja Rosda Karya.

Alquriyah, Y., Suciati., \& Prayitno, B. A. (2014). Pengembangan Modul Biologi Berbasis Reasoning and Problem Solving disertai Concept Mapping Tipe Network Tree pada Materi Pencemaran Lingkungan untuk Memberdayakan Keterampilan Proses Sains dan Kemampuan Mengevaluasi. Bioedukasi: Jurnal Pendidikan Biologi, 7(2), $27-31$. https://doi.org/10.20961/bioedukasi-uns.v7i2.2934

Auditor, E., \& Naval, D. (2014). Development and Validation of Tenth Grade Physics Modules Based on Selected. International Journal of Education on Research, 2(12), 145-152.

Bastian, I. (2006). Akuntansi Pendidikan. Jakarta: Erlangga.

Bergman, E. M., Bruin, A. B. H. De, Vorstenbosch, M. A. T. M., Kooloos, J. G. M., Puts, G. C. W. M., Leppink, J., Vleuten, C. P. M. Van Der. (2015). Effects of Learning Content in Context on Knowledge Acquisition and Recall: A Pretest-Posttest Control Group Design. Medical Education, 15(133), 1-11. https://doi.org/10.1186/s12909-015-0416-0

Billings, D. M., \& Halstead, J. A. (2016). Teaching in Nursing: A Guide for Faculty. United States: Elsevier Inc.

Bowman, J. (2014). Online Learning in Music: Foundations, Frameworks, and Practices. United States: Oxford University Press.

Branch, R. M. (2009). Instructional Design: The ADDIE Approach. New York: Springer.

Colthorpe, K. L., Abe, H., \& Ainscough, L. (2018). How do Students Deal with Difficult Physiological Knowledge? Advances Physiology Education, 42, 555-564. https://doi.org/10.1152/advan.00102.2018

Davis, T. (2015). Visual Design for Online Learning. United States: Wiley Publisher.

Depdiknas. (2008). Pengembangan Bahan Ajar. Jakarta: Depdiknas.

Direktorat Tenaga Kependidikan. (2008). Penulisan Modul. Jakarta: Direktorat Tenaga Kependidikan.

Drăghicescu, L. M., Petrescu, A.-M., Cristea, G. C., Gorghiu, L. M., \& Gorghiu, G. (2014). Application of Problem-Based Learning Strategy in Science lessons-Examples of Good Practice. Procedia Social and Behavioral Science, 149, $297-301$.

Fitzpatrick, C. (2008). A Problem Based Learning (PBL) Module on Electronics \& the Environment. Ireland.

Hapsari, N., Suyanto, S., \& Budiwati. (2016). Pengembangan E-Modul Pengayaan Materi Pertumbuhan dan Perkembangan untuk Meningkatkan Kemandirian dan Hasil Belajar. Jurnal Pendidikan Biologi, 5(5), 23-31.

Hartoyo. (2009). Upaya Meningkatkan Prestasi melalui Pembelajaran dengan Modul Berbasis Kompetensi. Jurnal Pendidikan Teknologi dan Kejuruan, 18(1), 61-84.

Mahendra, B., Krisnatuti, D., Tobing, A., \& Alting, B. Z. A. (2008). Care Your Self: Diabetes Mellitus. Jakarta: Niaga Swadaya.

Michael, J. (2007). What Makes Physiology Hard for Students to Learn ? Results of a Faculty Survey. Advances Physiology Education, 31(1), 34-40.

Prastowo, A. (2012). Panduan Kreatif Membuat Bahan Ajar Inovatif. Yogyakarta: Diva Press.

Suarsana, I. M., \& Mahayukti, G. A. (2013). Pengembangan E-Modul Berorientasi Pemecahan Masalah untuk Meningkatkan Keterampilan Berpikir Kritis Mahasiswa. Jurnal Pendidikan Indonesia, 2(2), 193-200. http://dx.doi.org/10.23887/jpiundiksha.v2i2.2171

Sudarno., Sunarno, W., \& Sarwanto. (2015). Pengembangan Modul IPA Terpadu Berbasis Kontekstual dengan Tema Pembuatan Tahu KelaS VII SMP Negeri 2 Jatiyoso. Inkuiri: Jurnal Pendidikan IPA, 4(3), 104-111.

Sungkono. (2009). Pengembangan dan Pemanfaatan Bahan Ajar Modul Dalam Proses Pembelajaran. Majalah Ilmiah Pembelajaran, 5(1).

Syamsul, A., \& Kusrianto, A. (2008). Sukses Menulis Buku Ajar dan Referensi. Surabaya: Grasindo.

Yokhebed. (2018). Peningkatan Keterampilan Pemecahan Masalah melalui Pembelajaran dengan Modul Berbasis Potensi Lokal pada Calon Guru Biologi. Edukasi: Jurnal Pendidikan, 16(2), 235-243. http://dx.doi.org/10.31571/edukasi.v16i2.966 